\title{
Percutaneous removal of a catheter fragment from the right atrium
}

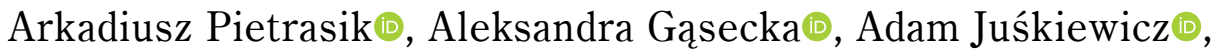 \\ Piotr Lewandowski®, Daria Stelmach®, Janusz Kochman® \\ $1^{\text {st }}$ Chair and Department of Cardiology, Medical University of Warsaw, Poland
}

A 73-year-old woman treated with chemotherapy was admitted to the surgery department due to the disruption and migration of a fragment of a permanent port-a-cath (Ambix Intraport, Fresenius Kabi, Dublin, Ireland) to the right heart chambers. At admission, the patient was asymptomatic and in good general condition. Chest radiogram confirmed the presence of the disrupted fragment of the catheter within the right heart chambers, in the right atrium and right ventricle (Fig. 1A). Ultrasonography revealed no foreign bodies in the right subclavian vein and within the subcutaneous tissue under the right clavicle.

The patient was consulted within the local Pulmonary Embolism Response Team (PERT) a multidisciplinary team designed to evaluate the risk of acute pulmonary embolism and determine the optimal therapy. Regarding the stable clinical condition of the patient and the risk of iatrogenic pulmonary embolism, which might result in hemodynamic destabilization, the patient qualified for interventional removal of the disrupted catheter fragment. Percutaneous removal of the catheter was attempted through the right femoral vein, using the Exeter Snare ES 15 loop. The loop was placed at one end of the catheter and tightened (Fig. 1B). The catheter was moved sequentially into the abdominal part of the inferior vena cava (Fig. 1C) and removed through the femoral vein in one piece (Fig. 1D, Suppl. Video 1). The disrupted part of the catheter was not further fractured or damaged. There were no complications following the procedure. New port-a-catheter was re-inserted and the patient was able to continue the chemotherapy.

Informed consent was obtained from patient for publication of this case report.

Conflict of interest: None declared

Address for correspondence: Aleksandra Gąsecka, $\mathrm{MD}, \mathrm{PhD}, 1^{\text {st }}$ Chair and Department of Cardiology, Medical University of Warsaw, ul. Banacha 1a, 02-097 Warszawa, Poland, tel: +48 2259919 51, e-mail: aleksandra.gasecka@wum.edu.pl

Received: 17.04.2021 Accepted: 5.08.2021

This article is available in open access under Creative Common Attribution-Non-Commercial-No Derivatives 4.0 International (CC BY-NC-ND 4.0) license, allowing to download articles and share them with others as long as they credit the authors and the publisher, but without permission to change them in any way or use them commercially. 

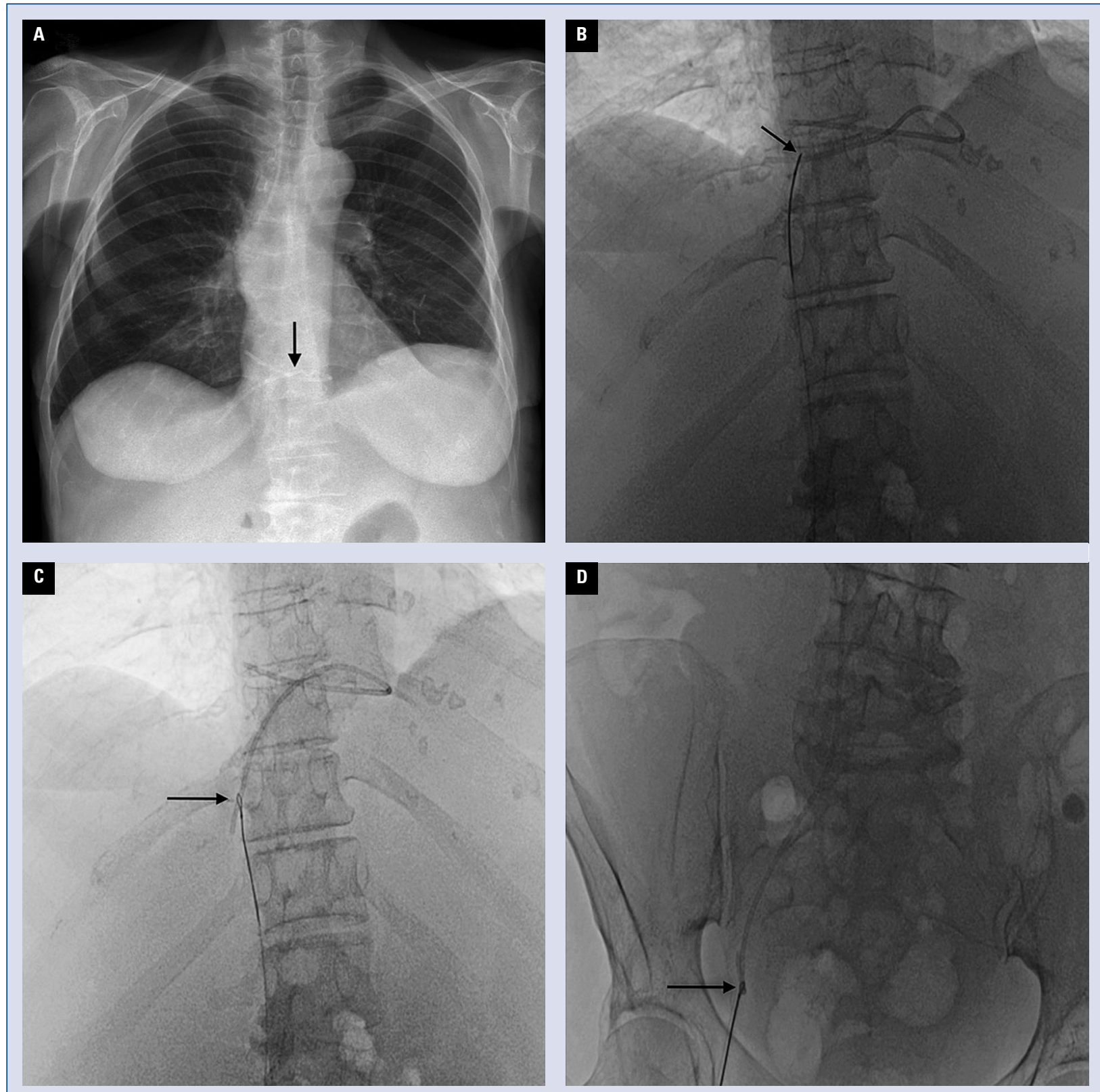

Figure 1. A. Chest radiogram made on admission showing fragment of the catheter within the right heart chambers (arrow); B. The Exeter Snare ES 15 loop tightened at one end of the catheter (arrow); C. The catheter was moved to the abdominal part of the inferior vena cava (arrow); D. Then relocated to the femoral vein and further removed through it (arrow). 